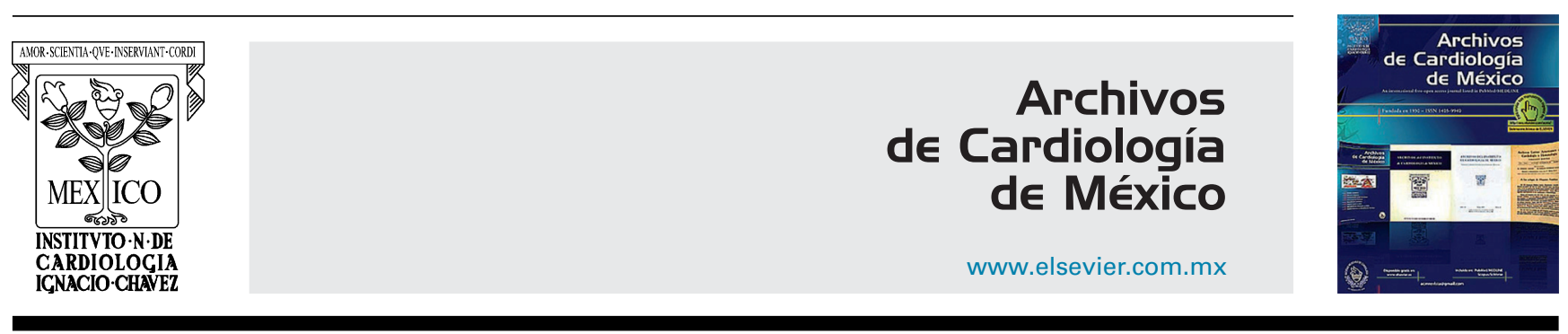

IMAGE IN CARDIOLOGY

\title{
Left ventricular non-compaction associated with bicuspid aortic valve and aortic coarctation
}

\section{No compactación del ventrículo izquierdo asociada con válvula aórtica bicúspide y coartación de aorta}

\author{
Nestor A. Parra-Ordoñez, Nydia Avila-Vanzzini, Nilda Espinola-Zavaleta*
}

Laboratory of Echocardiography, National Institute of Cardiology Ignacio Chavez, Mexico City, Mexico

Received 29 November 2016; accepted 30 March 2017

Male 18 years old, who began with data of heart failure. The transthoracic echocardiogram showed severe tricuspid regurgitation and pulmonary hypertension with SPAP of $90 \mathrm{mmHg}$, bicuspid aortic valve (BAV) with moderate aortic regurgitation, and juxtaductal aortic coarctation.

On physical examination, a cardiac apical impulse was palpated, near the midclavicular line in the sixth left intercostal space. I sound was duplicated by click aortic opening, II sound with physiological splitting and reinforced, aortic systolo-diastolic murmur and a mitral rumble was heard. The peripheral pulses were googly. An interventional treatment of aortic coarctation was performed with Palmaz stent and the patient was kept on medical treatment.

In the follow-up, the last echocardiographic study showed severe aortic regurgitation and left ventricular hypertrabeculations with noncompacted/compacted ratio

\footnotetext{
* Corresponding author at: Laboratory of Echocardiography, National Institute of Cardiology Ignacio Chávez, Juan Badiano No.

1, Colonia Sección XVI, Tlalpan, Mexico City, Mexico.

E-mail address: niesza2001@hotmail.com

(N. Espinola-Zavaleta).
}

in short axis at the level of papillary muscle of 3.1, not commented previously, left ventricular dilatation and systolic dysfunction with left ventricular ejection fraction of $40 \%$, moderate tricuspid regurgitation and moderate pulmonary hypertension with sPAP of $64 \mathrm{mmHg}$ and residual coartaction gradient of $40 \mathrm{mmHg}$ (Fig. 1). The patient is waiting for aortic valve replacement, but left ventricular non-compaction (LVNC) with left ventricular systolic dysfunction and pulmonary hypertension will modify his surgical prognosis.

Noncompacted cardiomyopathy is characterized by the absence of ventricular compaction and the persistence of deep intertrabecular recesses. The ventricular myocardium is compacted at 5-8 weeks of gestation, progressing from the epicardium to the endocardium and from the base to the apex, reducing the intertrabecular spaces to conform capillaries. The echocardiographic diagnosis is made based on the criteria of Jenni et al. previously described. An end-systolic ratio of non-compacted/compacted layers should be greater than $2 .^{1}$

The differential diagnosis should be made with apical hypertrophic cardiomyopathy, dilated cardiomyopathy and with the presence of apical thrombi, diagnoses that are 


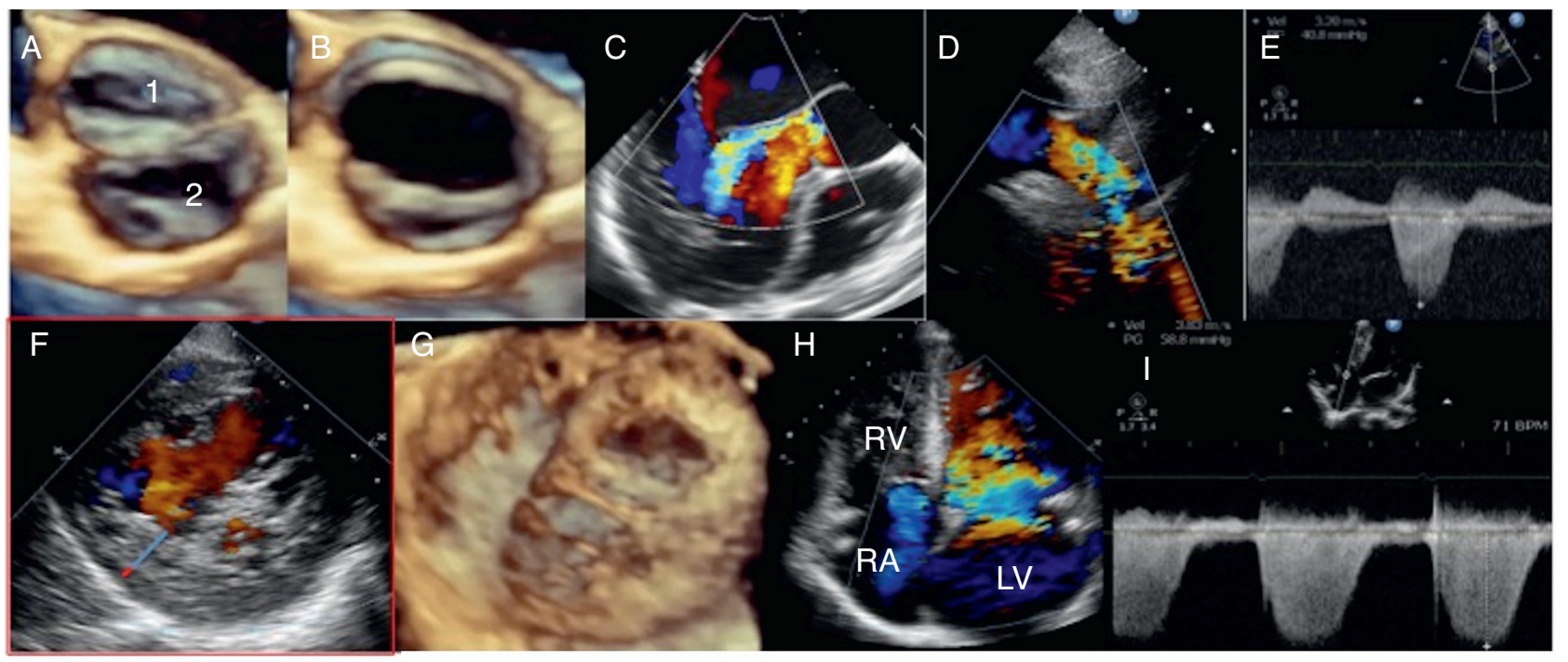

Figure 1 Transthoracic bidimensional, continuous and color Doppler and three-dimensional transesophageal echocardiography showing bicuspid aortic valve in diastole $(A)$ and systole $(B)$, aortic regurgitation $(C)$, residual aortic coarctation (D and $E$ ), ratio non-compacted (blue line)/compacted (red line) layers of $3.1(\mathrm{~F})$, left ventricular spongy aspect in transgastric view (G), moderate tricuspid regurgitation $(\mathrm{H})$ and moderate pulmonary hypertension $(\mathrm{I})$.

discarded using intravenously contrast Definity. In the literature a concomitant BAV and LVNC was found in $11 \%$ of a BAV population. ${ }^{2}$

\section{Ethical disclosures}

Protection of human and animal subjects. The authors declare that no experiments were performed on humans or animals for this study.

Confidentiality of data. The authors declare that no patient data appear in this article.
Right to privacy and informed consent. The authors declare that no patient data appear in this article.

\section{References}

1. Jenni R, Oechslin E, Schneider J, et al. Echocardiographic and pathoanatomical characteristics of isolated left ventricular non-compaction: a step towards classification as a distinct cardiomyopathy. Heart. 2001;86:666-71.

2. Agarwal A, Khandheria BK, Paterick TE, et al. Left ventricular noncompaction in patients with bicuspid aortic valve. J Am Soc Echocardiogr. 2013;26:1306-13. 